\title{
PERFORMANCE OF PLATE HEAT EXCHANGERS WITH ODD NUMBER OF CHANNELS
}

\author{
M. Khalil Bassiouny \\ Minufiya University, Faculty of Engineering, Mechanical Power \\ Department, Shebin El-Kom, Egypt
}

\section{ABSTRACT}

This paper deals with a numerical analysis of the heat transfer behavior in gasketed plate heat exchangers with an odd number of parallel arranged channels (case of half-unsymmetrical channels). The calculations are carried out under varying the number of transfer units, the heat capacity rate ratios and the number of channels for both cases of co-current and counter-current flow regimes.

A computer program is established to predict the temperature distribution in the channels, the heat exchanger effectiveness and the correction factor of the logarithmic mean temperature difference. For this purpose, a combination of Jacobian iteration method and Gaussian elimination method is applied to solve exactly the system of coupled differential equations governing the temperature distribution in terms of exponential functions. The computer program is extended to cover the case of even number of channels (case of complete unsymmetrical channels) for the sake of comparison. Furthermore, deduced formulae for predicting the limit values of the correction factor as a function of the number of channels and the heat capacity rate ratio are also presented.

It is shown that both the effectiveness and the correction factor have high values in case of counter-flow specially at equal capacity rates than in case of parallel flow. The results indicate also that the correction factor falls slowly with increasing the effectiveness, the total number of transfer units and the total heat capacity rate ratio to reach certain higher limit values in case of countercurrent flow regimes, while it falls down steeply to approach very low values in case of co-current flow regimes.

Manuscript received from Dr. M. Khalil Bassiouny

Accepted on : $23 / 6 / 2001$

Engineering Research Journal Vol 24,No 3, 2001 Minufiya University, Faculty Of

Engineering, Shebien El-Kom, Egypt, ISSN 1110-1180 
The rate of heat transfer with plate units of odd number of channels is more than that with even number in all cases except in units undergoing evaporation or condensation processes we have the other way round at the limit case. This means an addition of another thermal plate causes a substantial change in the heat transfer characteristics of plate heat exchangers.

Keywords: Plate heat exchangers, heat transfer, performance, mathematical model, numerical methods.

\section{INTRODUCTION}

The gasketed plate heat exchanger consists of corrugated metal plates, which have four ports, one in each corner. The embossing of the plates results in a narrower flow passage and in many changes of section and direction. Generally, this performs three functions. It increases the effective heat transfer surface. It gives rigidity and strength by providing a multiplicity of support points against collapse of the channels by high pressures on the opposite side of the boundary plates. Finally, it promotes turbulence which reduces the fluid film resistance to heat transfer. The plates are sealed at their outer edges by gaskets to prevent leakage to the surrounding atmosphere. Fluid flow into the channels is controlled by the presence or absence of gaskets around the ports. These gaskets are arranged so that the heating and cooling media are directed alternately into the passages formed between the plates. Typical average gaps between the plates are 2 to $5 \mathrm{~mm}$. A plate thickness of only $0.7 \mathrm{~mm}$ is now capable of handling pressure up to 16. bar.

Besides the common field of applications of plate heat exchangers in the industry, for example in chemical and food industry, they are nowadays widely used in nuclear power plants, steam power stations, solar energy units, air conditioning plants, heat pumps, industrial heat recovery, utilization of geothermal gradient, petroleum industry, ship building, machine industry, textile industry, paper and cellulose industry, soap and washing powder industry as well as production of sulphuric acid. These multiple fields of applications indicate the importance of plate heat exchangers for the future. The reasons for the widening popularity of plate heat exchangers are in their greater compactness and accessibility of heat transfer surfaces as compared with those of conventional shell and tube heat exchangers. Plate units can also be easily assembled and reassembled in any size or arrangement of passes.

The characteristics, design and applications of gasketed plate heat exchangers have been described further in a number of papers [ 1 - 28]. The heat transfer and flow behavior as well as the methods of improving their effectiveness have only been handled in the past few years and described in a number of papers [29-49]. Simth and Troupe [50] and Wang et al [51] carried out experimental studies for obtaining pressure drop correlations useful in plate heat exchanger design. Correlations for both the friction factor and heat transfer film coefficients in the channels of plate heat exchangers are presented by Talik et al [52], Edwards et 
al [53], Jackson and Troupe [54] as well as Kovalenko and Obolentsev [55]. The effect of chevron angle on the thermal - hydraulic performance of plate heat exchangers is investigated by Muley and Manglik [56,57] and Heggs et al [58]. Theoretical studies about flow distribution and pressure drop in the U - and Z - . type arrangements plate heat exchangers are carried out by the author of the present paper $[59,60]$. Investigations concerning the heat transfer analysis in the channels of plate heat exchangers involving the effect of the two insulated boundary plates are presented by the author in Ref. [61] for the case of four channels and in Ref. [62] for the case of five channels. The problem of heat transfer in a single pass plate heat exchanger with an even number of channels, which have two types of unsymmetry namely, working media and heat transfer unsymmetries, is studied also by the author $[63,64]$.

Theoretical and experimental investigations about pressure drop and heat transfer in spiral plate heat exchangers, which has similar end effects due to the unsymmetrical heat transfer in the inner and outer channels are published elsewhere [65-69].

The aim of such heat exchangers in the different industrial processes is to verify a high effectiveness. For this purpose, the ideal case of pure countercurrent flow heat exchanger should be reached as near as possible. Some factors in the technical field of applications prevent the achievement of the ideal case. Such factors which has a bad effect on the effectiveness are coming about the heat transfer and working media unsymmetries. The heat transfer unsymmetry, which occurs because the fluid in the boundary channels exchanges heat with one side only while all internal substreams are in heat transfer with two sides, exists in all plate heat exchangers either with even or with odd number of parallel channels. The working media unsymmetry, which takes place when the first and the last channel has different heat capacity rates, is to be found only in plate heat exchangers with even number of parallel channels. Therefore, there are two types of unsymmetry in plate heat exchangers with even number of parallel channels (this case will be mentioned as complete unsymmetrical case) while only one type of unsymmetry exists in plate heat exchangers with odd number of parallel channels (this case will be called as half-unsymmetrical case).

The problem of heat transfer in a five channel plate heat exchanger could be treated analytically [62]. For greater odd number of channels the calculations must be numerically extended because the number of coupled differential equations describing the temperature distribution in the channels is equal to the number of channels. The results for a five channels plate heat exchanger showed that reversed heat transfer may take place in a part of the two middle thermal plates in the case of co-current flow regime. Moreover, the correction factor of the logarithmic mean temperature difference varies between 1 and 0.5 depending on the total number of transfer units and the heat capacity rate ratio. It decreases always with the increase of $N T U_{t}$ to approach limiting values between 0.75 and 0.9 for counter-current flow regimes and values between 0.5 and 0.75 for cocurrent flow regimes as $N T U_{t}$ approaches $\infty$. 
The aim of the present paper is to investigate the heat transfer behavior in plate heat exchangers with an odd number of parallel channels more than five channels, which is applied actually in the industry to achieve a sufficient heat transfer area. The analysis will be carried out under varying the number of channels, the number of transfer units and the heat capacity rate ratio. Moreover, to compare the present work with some available results for heat transfer in plate heat exchangers having an even number of parallel arranged channels [64].

\section{THEORETICAL ANALYSIS}

\section{Governing equations}

The low capacity rate medium is assumed to flow through the odd-numbered channels, while the high capacity rate medium is allowed to flow through the even-numbered channels. An energy balance on a fluid element, as shown in Fig.1, is performed to obtain the differential equations describing the temperature distribution in the channels. Considering Fig. 1a, the energy balance yields the following equation:
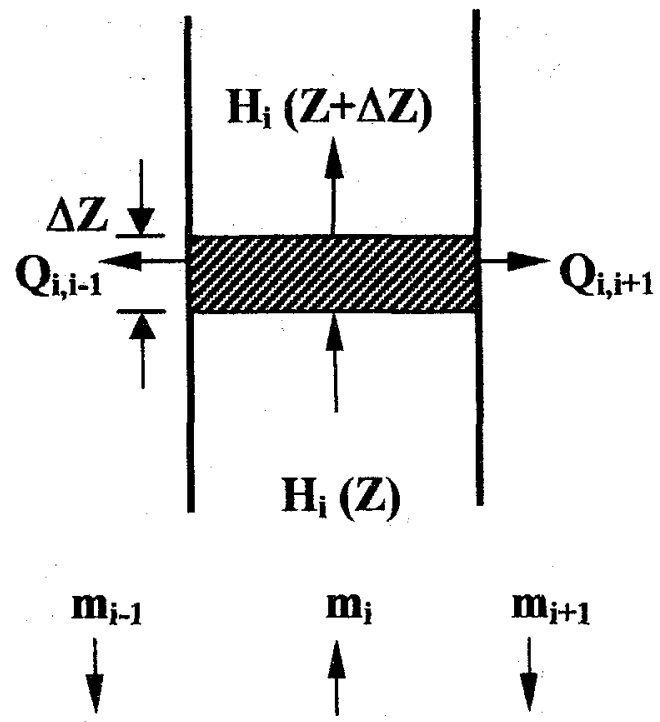

(a)
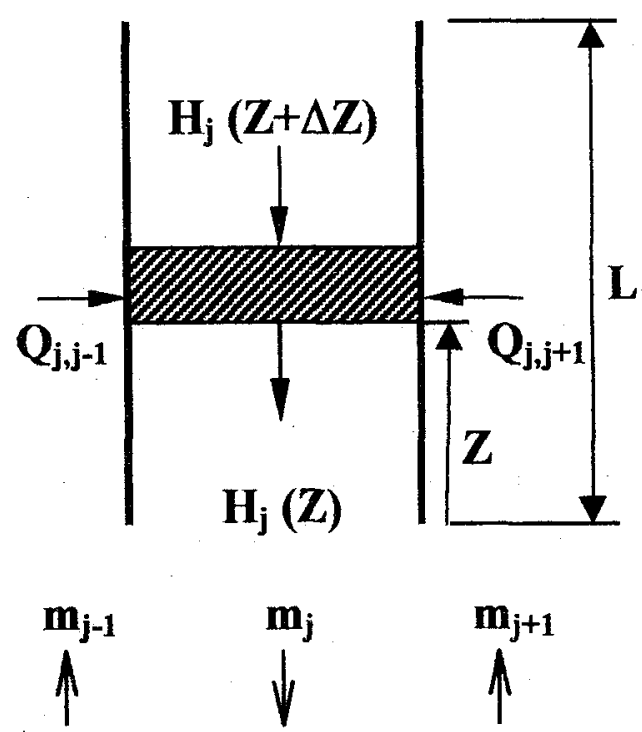

(b)

Fig. 1: A fluid element in the channels of a gasketed plate heat exchanger

$$
\Delta \dot{Q}_{i, i-1}+\Delta \dot{Q}_{i, i+1}=\dot{H}_{i}(Z)-\dot{H}_{i}(Z+\Delta Z)=-\frac{d \dot{H}_{i}(Z)}{d Z} \Delta Z .
$$

Through applying Newton's law of convection where

$$
\begin{aligned}
& \Delta \dot{Q}_{i, i-1}=U_{i-1, i} \Delta A\left(T_{i-1}-T_{i}\right), \text { and } \\
& \Delta \dot{Q}_{i, i+1}=U_{i+1, i} \Delta A\left(T_{i+1}-T_{i}\right) .
\end{aligned}
$$

Taking into account that $H_{i}=\dot{M}_{i} C_{p} T_{i}$ and $\Delta A=S . \Delta Z$, one obtains 


$$
\frac{d T_{i}}{d Z}=\frac{U_{i-1, i} S}{\dot{M}_{i} C_{p i}}\left(T_{i-1}-T_{i}\right)+\frac{U_{i+1, i} S}{\dot{M}_{i} C_{p i}}\left(T_{i+1}-T_{i}\right),
$$

where $i=1,3,5, \ldots \ldots$.

Similarly, the energy balance on the fluid element shown in Fig. $1 \mathrm{~b}$ gives

$$
\frac{d T_{j}}{d Z}=\frac{U_{j-1, j} S}{\dot{M}_{j} C_{p j}}\left(T_{j-1}-T_{j}\right)+\frac{U_{j+1, j} S}{\dot{M}_{j} C_{p j}}\left(T_{j+1}-T_{j}\right),
$$

where $j=2,4,6, \ldots \ldots$.

Upon substituting the following dimensionless variables

$$
\theta=\frac{T-T_{h, i n}}{T_{l, i n}-T_{h, i n}}, \quad N T U=\frac{U A}{\dot{M} C_{p}}, \quad z^{*}=\frac{Z}{L}
$$

into eqns (2) and (3), one obtains

$$
\begin{aligned}
& \frac{d \theta_{i}}{d z^{*}}=N T U_{i-1, i} \theta_{i-1}-\left(N T U_{i-1, i}+N T U_{i+1, i}\right) \theta_{i}+N T U_{i+1, i} \theta_{i+1} \\
& \frac{d \theta_{j}}{d z^{*}}=N T U_{j-1, j} \theta_{j-1}-\left(N T U_{j-1, j}+N T U_{j+1, j}\right) \theta_{j}+N T U_{j+1, j} \theta_{j+1} \ldots
\end{aligned}
$$

The two subscripts in the term NTU refer to the two streams for calculating the overall heat transfer coefficient $U$, while the second subscript alone concerns the stream number for computing NTU. For a plate heat exchanger of a single pass and odd parallel number of channels having uniform flow distribution in the channels, the system of differential equations governing the temperature distribution in the channels can be given using eqns. (4) and (5) as follows:

$$
\begin{aligned}
& \frac{d \theta_{1}}{d z}=-\theta_{1}+\theta_{2} \\
& \frac{d \theta_{2}}{d z}=C\left(\theta_{1}-2 \theta_{2}+\theta_{3}\right) \\
& \frac{d \theta_{3}}{d z}=\theta_{2}-2 \theta_{3}+\theta_{4}
\end{aligned}
$$

$$
\begin{aligned}
& \frac{d \theta_{n-2}}{d z}=\theta_{n-3}-2 \theta_{n-2}+\theta_{n-1} \\
& \frac{d \theta_{n-1}}{d z}=C\left(\theta_{n-2}-2 \theta_{n-1}+\theta_{n}\right) \\
& \frac{d \theta_{n}}{d z}=\theta_{n-1}-\theta_{n}
\end{aligned}
$$

where, $z=N T U_{1} z^{*}$ and

$$
C=\frac{\left(\dot{M} C_{p}\right)_{l}}{\left(\dot{M} C_{p}\right)_{h}}=\frac{N T U_{h}}{N T U_{l}},
$$


which has positive, zero or negative values for a single phase with co-current flow, change of phase (evaporation / condensation) or a single phase with counter-current flow respectively.

\section{Boundary Conditions}

The boundary conditions associated with eqn. (6) are

$$
\theta_{1}=\theta_{3}=\theta_{5}=\ldots \ldots \ldots \ldots . . . .=\theta_{n}=1 \text {, at } z=0
$$

and

$$
\theta_{2}=\theta_{4}=\theta_{6}=\ldots \ldots \ldots \ldots \ldots=\theta_{n-l}=0, \text { at } z=0
$$

for co-current flow regimes, and

$$
\theta_{1}=\theta_{3}=\theta_{5}=\ldots \ldots \ldots \ldots . . . . .=\theta_{n}=1 \text {, at } z=0
$$

and

$$
\theta_{2}=\theta_{4}=\theta_{6}=\ldots \ldots \ldots \ldots \ldots=\theta_{n-l}=0 \text {, at } z=N T U_{l}
$$

for counter-current flow regimes.

\section{Heat Exchanger Effectiveness}

In order to determine the effectiveness of the heat exchanger based, for example, on the low heat capacity rate medium (hot side), the mean outlet temperature of these channels should be calculated using the following expression:

$$
\bar{\theta}_{l, \text { out }}=\frac{\theta_{1, \text { out }}+\theta_{3, \text { out }}+\theta_{5, \text { out }}+\ldots \ldots \ldots \ldots+\theta_{\text {nout }}}{(n+1) / 2} .
$$

The computation of the effectiveness is now possible by applying the relation

$\varepsilon=\frac{T_{l, \text { in }}-\bar{T}_{l, \text { out }}}{T_{l, \text { in }}-T_{h, \text { in }}}=1-\bar{\theta}_{l, \text { out }}$.

\section{Correction Factor}

As a result of the end effect, unsymmetrical heat transfer between the channels will be obtained. Therefore, a correction factor $F$ must be calculated and applied to the logarithmic mean temperature difference in the equation of convective heat flow to have the correct mean fluid temperature. This factor is defined as

$$
F=\frac{\overline{\Delta T}}{\Delta T_{L M}}
$$

or in another form

$$
F=\frac{\dot{Q} / U A_{t}}{\Delta T_{L M}},
$$

where $A_{t}=(n-1) A$.

According to [61], the correction factor can be given as a function of the effectiveness and the number of transfer units. These relations may be written for the cases of parallel and counter flow respectively as follows: 


$$
F_{p}=\frac{1}{N T U_{t}\left(1+C_{t}\right)} \ln \left[\frac{1}{1-\varepsilon\left(1+C_{t}\right)}\right]
$$

and

$$
F_{c}=\frac{1}{N T U_{t}\left(1+C_{t}\right)} \ln \left[1+\left(1+C_{t}\right) \frac{\varepsilon}{1-\varepsilon}\right]
$$

For odd number of channels, we have

$$
\begin{aligned}
& N T U_{t}=\frac{(n-1)}{(n+1) / 2} \text { NTU, } \\
& C_{t}=\frac{n+1}{n-1} C .
\end{aligned}
$$

In eqns. (9) and (10), $C_{t}$ takes positive values for parallel (co-current) flow, while it takes negative values for counter-current flow.

\section{NUMERICAL TREATMENT}

Equations (6) are a system of coupled ordinary differential equations of the first order with constant coefficients. The method of exponential function [70] is applied to solve these equations. For this purpose, the general solution for $\mathbf{n}$ channels

$$
\theta_{k}=\sum_{m=1}^{n} a_{k m} e^{\lambda_{m} \cdot z}
$$

is substituted in the system of differential equations, where

$a_{k n}$ are the coefficients of the exponential function,

$\lambda_{m}$ are the eigenvalues,

$n$ is the total number of channels, and

$k$ is the run number of the channel considered.

The eigenvalues $\lambda_{m}$ of the coefficient matrix $A^{*}$, where

$$
A^{*}=\left\|\begin{array}{cccccccccc}
-1 & 1 & 0 & 0 & . & . & 0 & 0 & 0 & 0 \\
C & -2 C & C & 0 & . & . & 0 & 0 & 0 & 0 \\
0 & 1 & -2 & 1 & . & . & 0 & 0 & 0 & 0 \\
. & . & . & . & . & . & . & . & . & . \\
. & . & . & . & . & . & . & . & . & . \\
0 & 0 & 0 & 0 & . & . & 1 & -2 & 1 & 0 \\
0 & 0 & 0 & 0 & . & . & 0 & C & -2 C & C \\
0 & 0 & 0 & 0 & . & . & 0 & 0 & 1 & -1
\end{array}\right\|
$$

are determined by solving the characteristic equation

$$
\left|A^{*}-\lambda_{m} I\right|=0
$$


numerically using Jacobian iteration method, where $I$ is the unit matrix. In order to obtain the general solution, the coefficients of the exponential functions $a_{k m}$ in eqn. (13) must be determined. From the linear algebraic system of equations

$$
\left(A^{*}-\lambda_{m} I\right) B_{k m}=0
$$

where, $B_{k m}=\frac{a_{k m}}{a_{1 m}}$,

the coefficient ratios $B_{k m}$ can be obtained numerically by applying Gaussian elimination method. The substitution of the boundary conditions in eqn. (13) supplies also a system of linear algebraic equations in the n unknowns $a_{1 m}$ from which, the coefficients $a_{k m}$ can be ascertained.

For achieving this purpose, a computer program is written to solve the differential equations (6) for determining the temperature distribution in the channels of the considered type of plate heat exchanger, the effectiveness and the LMTD-correction factor.

\section{Case of infinite capacity rates $\left(C_{t}=0\right)$}

\section{1) Odd number of channels}

When $C_{t}=C=0$, the solution of eqn.(6), associated with the boundary conditions that

$$
\theta_{1}=\theta_{3}=\theta_{5}=\ldots \ldots \ldots=\theta_{n-2}=\theta_{n}=1 \text { at } \mathrm{z}=0 \text {, }
$$

and

$$
\begin{aligned}
& \theta_{2}=\theta_{4}=\theta_{6}=\ldots \ldots \ldots=\theta_{n-3}=\theta_{n-1}=0 \text { at all } \mathrm{z}, \text { gives } \\
& \theta_{1}=\theta_{3}=\theta_{5}=\ldots \ldots \ldots=\theta_{n-2}=\theta_{n}=e^{-z} .
\end{aligned}
$$

This results in

$$
\varepsilon=1-\bar{\theta}_{\text {out }}=1-\frac{2 e^{-N T U}+\frac{n-3}{2} e^{-2 N T U}}{\frac{n+1}{2}} .
$$

After rearranging the terms and making use of eqn. (11), one obtains

$$
\varepsilon=1-\frac{4}{n+1} e^{-\frac{n+1}{2(n-1)} N T U_{t}}-\frac{n-3}{n+1} e^{-\frac{n+1}{n-1} N T U_{t}} \text {. }
$$

Let $x=e^{-\frac{(n+1)}{2(n-1)} N T U_{t}}$,

or $\quad N T U_{t}=-\frac{2(n-1)}{n+1} \ln x$.

Through substituting eqn. (18) into eqn. (17), the following relation yields

$$
\frac{n-3}{n+1} x^{2}+\frac{4}{n+1} x-(1-\varepsilon)=0 \text {. }
$$

Solving eqn. (20), taking into account that $x$ must be only positive, we reach at

$$
x=[\sqrt{4+(n-3)(n+1)(1-\varepsilon)}-2] /(n-3) \text {. }
$$

Resubstituting eqn. (21) into eqn. (19), one gets 


$$
N T U_{t}=\frac{2(n-1)}{n+1} \ln \frac{(n-3)}{\sqrt{4+(n-3)(n+1)(1-\varepsilon)}-2} .
$$

The substitution of eqn. (22) into eqn. (9) with $C_{t}=0$ yields the final relation for $F$ as a function of both $n$ and $\varepsilon$ :

$$
F=\frac{n+1}{2(n-1)} \frac{\ln (1-\varepsilon)}{\ln \{[\sqrt{4+(n-3)(n+1)(1-\varepsilon)}-2] /(n-3)\}} .
$$

The preceding relation holds only for odd number of channels with $C_{t}=0$ and $n>3$ because when $n=3, F=1$ (case of complete symmetry). The limit value of $F$ is calculated from eqn. (23) to be

$$
F_{\infty}=\lim _{\varepsilon \rightarrow 1} F=\frac{n+1}{2(n-1)} .
$$

\section{2) Even number of channels}

In a similar way, as derived above, the effectiveness of a plate heat exchanger having an even number of channels can be given directly as follows:

$$
\varepsilon=1-\frac{2}{n} e^{-\frac{n}{2(n-1)} N T U_{t}}-\left(1-\frac{2}{n}\right) e^{-\frac{n}{n-1} N T U_{t}} .
$$

The solution of the foregoing equation in $N T U_{t}$ results in

$$
N T U_{\mathrm{t}}=\frac{2(n-1)}{n} \ln \frac{(n-2)}{\sqrt{1+n(n-2)(1-\varepsilon)}-1} \text {. }
$$

After inserting eqn. (26) into eqn. (9), the relation connected $F$ with both $n$ and $\varepsilon$ for plate units with even number of channels can be put in the following form:

$$
F=\frac{n}{2(n-1)} \frac{\ln (1-\varepsilon)}{\ln \{[\sqrt{1+n(n-2)(1-\varepsilon)}-1] /(n-2)\}} .
$$

The previous equation holds only for even number of channels with $C_{t}=0$ and $n>2$ because when $n=2, F=1$ (case of complete symmetry). The limit value of $F$ is obtained from eqn. (27) to be

$$
F_{\infty}=\lim _{\varepsilon \rightarrow 1} F=\frac{n}{2(n-1)} .
$$

\section{The limit value of the correction factor}

The limit values of the correction factor $F_{\infty}$ for even number of channels in case of counter-current flow regime, as presented in ref. [64], are independent of the total heat capacity rate ratio and is given by

$$
F_{\infty}=\frac{n}{2(n-1)} .
$$

This result coincides exactly with that obtained by eqn. (28) for $C_{t}=0$. 
In case of odd number of channels, the limit values of $F$ depend on $C_{t}$. For $C_{t}=0$, these limit values can be determined from eqn. (24). In order to obtain similar relationships between $F_{\infty}$ and $n$ for $C_{t} \neq 0$, the effectiveness of the plate heat exchanger must be determined as a function of NTU. The analytical results for $n=5$ and the numerical analysis for higher number of channels indicate that the effectiveness for any number of channels can be put in the following form:

$$
\varepsilon=1-A_{1}-A_{2} e^{\lambda_{2} N T U}-A_{3} e^{\lambda_{3} N T U}-\ldots \ldots \ldots . . . A_{m} e^{\lambda_{m} N T U}
$$

where $\lambda_{2}, \lambda_{3}, \ldots ., \lambda_{m}$ are the eigenvalues and $\lambda_{1}$ is always equal to zero. $A_{1}, A_{2}, A_{3}, \ldots . ., A_{m}$ are constants which are independent from NTU. The constant $A_{1}$ is given by

$$
A_{1}=1-\frac{1}{1+C_{t}} \text {. }
$$

The relation between the correction factor and the effectiveness in the case of co-current flow regime can be written as follows:

$$
F=\frac{1}{N T U_{t}\left(1+C_{t}\right)} \ln \frac{1}{\Gamma}
$$

where, $\Gamma=1-\left(1+C_{t}\right) \varepsilon$.

By applying de l'Hospital theory on eqn. (32) and taking into account eqn. (11), the following equation will be obtained:

$$
F_{\infty}=\lim _{N T U \rightarrow \infty} F=\lim _{N T U \rightarrow \infty}\left\{-\frac{(n+1)}{2(n-1)\left(1+C_{t}\right)} \frac{\Gamma^{\prime}}{\Gamma}\right\}
$$

where, $\Gamma^{\prime}=\frac{d \Gamma}{d(N T U)}$.

The substitution of eqn. (30) into eqn. (33) and making use of eqn.(31) results in

$$
\begin{aligned}
& \Gamma=\left(1+C_{t}\right)\left(A_{2} e^{\lambda_{2} N T U}+A_{3} e^{\lambda_{3} N T U}+\ldots . .+A_{m} e^{\lambda_{m} N T U}\right) \\
& \Gamma^{\prime}=\left(1+C_{t}\right)\left(\lambda_{2} A_{2} e^{\lambda_{2} N T U}+\lambda_{3} A_{3} e^{\lambda_{3} N T U}+\ldots . .+\lambda_{m} A_{m} e^{\lambda_{m} N T U}\right) .
\end{aligned}
$$

Resubstituting the two foregoing equations into eqn. (34), we have

$$
F_{\infty}=\lim _{N T U \rightarrow \infty}\left\{-\frac{(n+1)}{2(n-1)\left(1+C_{t}\right)} \frac{\lambda_{2} A_{2} e^{\lambda_{2} N T U}+\lambda_{3} A_{3} e^{\lambda_{3} N T U}+\ldots+\lambda_{m} A_{m} e^{\lambda_{m} N T U}}{A_{2} e^{\lambda_{2} N T U}+A_{3} e^{\lambda_{3} N T U}+\ldots+A_{m} e^{\lambda_{m} N T U}}\right\}
$$

Through dividing the numerator and the denominator on $e^{\lambda_{s} N T U}$, where $\lambda_{s}$ is the negative smallest eignvalue, the limit value of $F$ can be recasted in the following form:

$$
F_{\infty}=-\frac{\lambda_{s}}{\left(1+C_{t}\right)} \frac{(n+1)}{2(n-1)}
$$

Once more, in case of $C_{t}=0$, when we return back to the analytical solution represented by 


$$
\theta_{1}=\theta_{3}=\theta_{5}=\ldots \ldots \ldots . .=\theta_{n-2}=\theta_{n}=e^{-z},
$$

we find that $\lambda_{s}=-1$ when $C_{t}=0$. Through substituting these values in eqn: (38), it will be reduced to the same form given by eqn. (24).

For $C_{t} \neq 0$ and higher values of $n(n>5), \lambda_{s}$ should be predicted numerically.

A similar derivation for the case of counter-flow leads to the same expression, which holds for all values of $C_{t}$ except $C_{t}=-1$.

As a check for the validity of eqn. (38), $F_{\infty}$ can be calculated in the case of five channels for different values of $C_{t}$ and then the results can be compared with those of the analytical solution [62]. For example: when $n=5$ and for cocurrent flow with $C_{t}=1$, from the numerical calculations $\lambda_{s}=\lambda_{2}=-1.333333$. By substituting $\lambda_{s}$ in eqn. (38) one obtains $F_{\infty}=0.5$. This result agrees accurately with that calculated from the analytical solution

$$
F_{\infty, n=5}=\frac{C_{t}+\frac{9}{4}-\sqrt{C_{t}^{2}+\frac{9}{16}}}{2\left(1+C_{t}\right)} \text {. }
$$

Another verification: for $n=5$ and $C_{t}=-0.75$, the numerical solution gives $\lambda_{s}=\lambda_{2}=-0.292893$. The substitution in eqn. (38) yields $F_{\infty}=0.878679$, which also agrees very well with the analytical prediction given by eqn. (39).

Equation (38) will be undefined for $C_{t}=-1$, therefore the limit values of $F$ are determined numerically for different values of $n$. The results are presented in Table 1.

\begin{tabular}{|c|c|c|c|c|c|c|c|}
\hline$n$ & 5 & 7 & 9 & 11 & 13 & 15 & 17 \\
\hline$F$ & $\begin{array}{c}0.9 \\
=9 / 10\end{array}$ & $\begin{array}{c}0.85714 \\
=6 / 7\end{array}$ & $\begin{array}{c}0.83333 \\
=5 / 6\end{array}$ & $\begin{array}{c}0.81818 \\
=9 / 11\end{array}$ & $\begin{array}{c}0.80769 \\
=21 / 26\end{array}$ & $\begin{array}{c}0.8 \\
=4 / 5\end{array}$ & $\begin{array}{c}0.79412 \\
=27 / 34\end{array}$ \\
\hline
\end{tabular}

Table 1: Numerical results for $F$ in case of odd number of channels and $C_{t}=-1$

A relationship between $F_{\infty}$ and $n$ can be developed from these values to be

$$
F_{\infty}=\frac{3}{4} \frac{(n+1)}{n} \text {. }
$$

\section{RESULTS AND DISCUSSION}

\section{Case of Five Parallel Channels}

The computer program is used first of all to obtain numerical results for the case of a five channel plate heat exchanger in order to examine the validity and the accuracy of this program through comparing the numerical results with those of the analytical treatment [62] at different values of $C_{t}$ and $N T U_{t}$. An exact agreement between the numerical and the analytical results is found, as shown in Fig. 2 for the heat exchanger effectiveness and in Fig. 3 for the correction factor 
of the logarithmic mean temperature difference. This means that the computer program can give accurate results for plate heat exchangers with higher number of parallel-arranged channels.

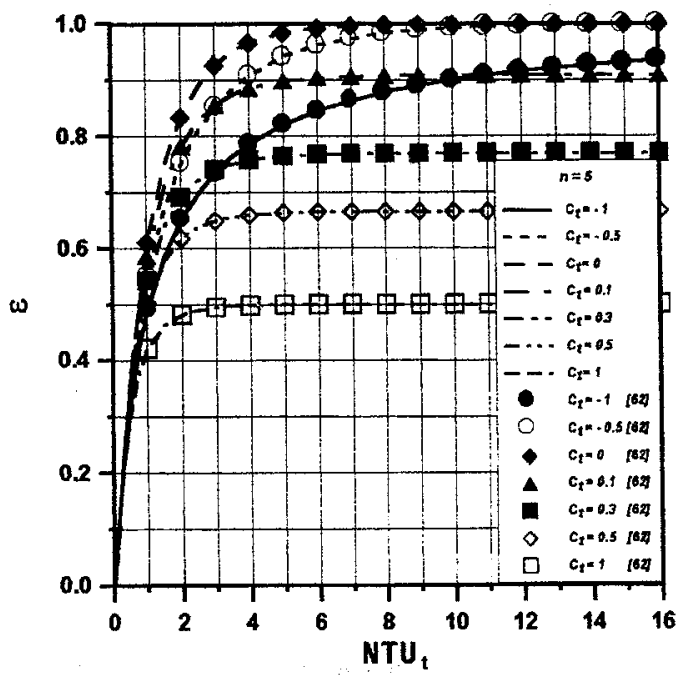

Fig. 2: Comparison between numerical and analytical results for $\varepsilon$ with $n=5$.

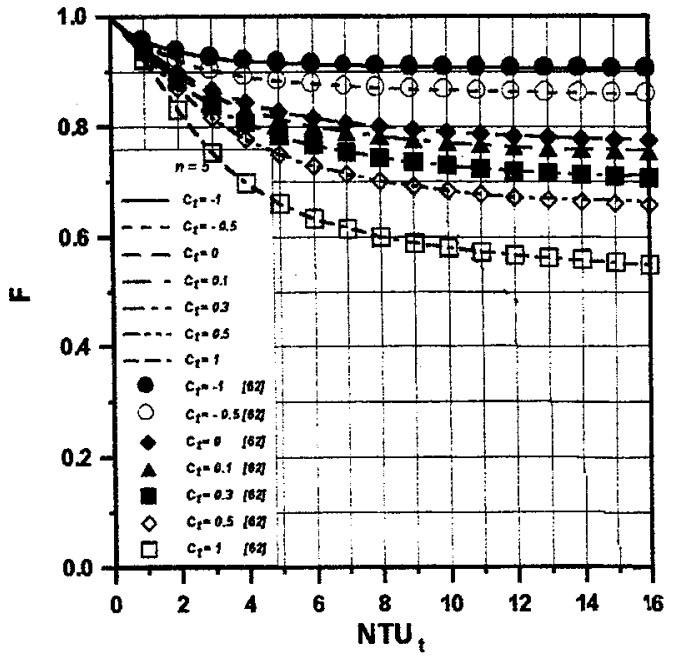

Fig. 3: Comparison between numerical and analytical results for $F$ with $n=5$.

\section{Case of Seven Parallel Channels}

Figure 4 represents the temperature distribution in both the heated and the cooled seven channels for counter-flow regime with $C_{t}=-1$ and $N T U_{t}=5$, while Fig. 5 shows the same distribution but for $N T U_{t}=10$.

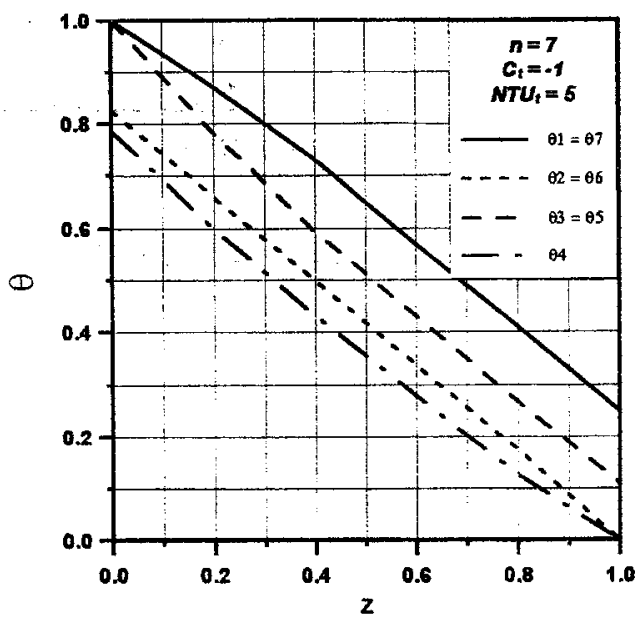

Fig. 4: Temperature distribution in a plate heat exchanger with $n=7$ and $N T U_{t}=5$.

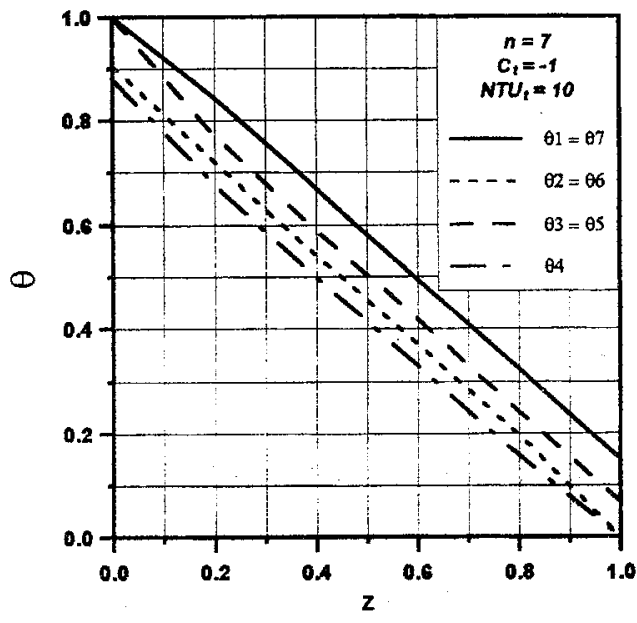

Fig. 5: Temperature distribution in a plate heat exchanger with $n=7$ and $N T U_{t}=10$.

It can be expected that the temperature curves for higher values of $N T U_{t}$ come more and more close to each other and consequently no heat transfer may occur over a considerable part of the thermal plate between channels 2 and 3 as 
well as between channels 5 and 6 . The LMTD - correction factor is indicated against the heat exchanger effectiveness in Fig. 6 with the total heat capacity rate ratio as a parameter. The correction factor falls down with the increase of the effectiveness slowly for counter-flow and rapidly for parallel flow. It reaches a value of $\frac{6}{7}$ for $C_{t}=-1$ and a value of $\frac{2}{3}$ for $C_{t}=0$, while it goes steeply down to reach very low values in case of parallel flow.

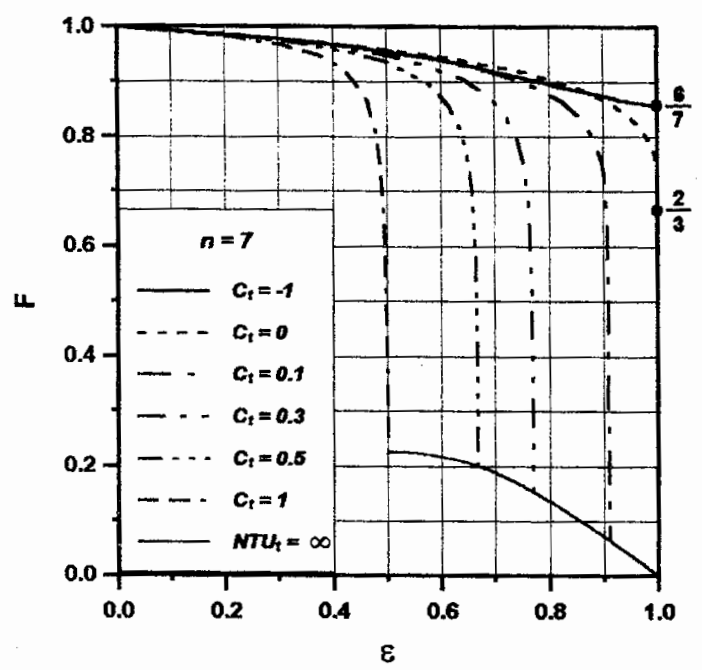

Fig. 6: Correction factor as a function of effectiveness for $n=7$.

Figures 7 and 8 show respectively the variation of the heat exchanger effectiveness and the LMTD - correction factor with the total number of transfer units at different values of the parameter $C_{t}$. The curves indicate that both $\varepsilon$ and $F$ have higher values in case of counter-flow specially at equal capacity rates than in the case of parallel flow.

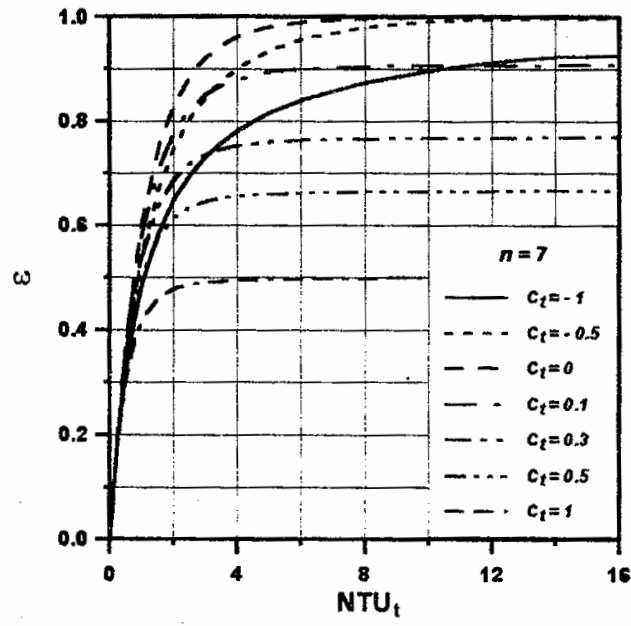

Fig. 7: Variation of effectiveness with $N T U_{t}$, for $n=7$.

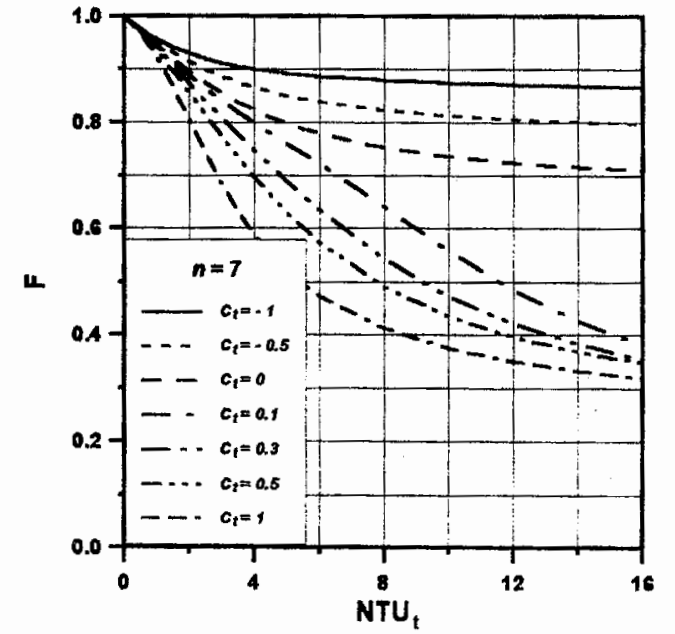

Fig. 8: Variation of correction factor with $N T U_{t}$, for $n=7$. 


\section{Case of Nine Parallel Channels}

The calculated temperature profiles in a nine channel plate heat exchanger for a case of counter-current flow regime with $C_{t}=-1$ are given in Fig. 9 for $N T U_{t}=5$ and in Fig. 10 for $N T U_{t}=10$. Vanishing heat transfer may be also obtained in parts of the thermal plates. This behavior is to be expected at high values of the number of transfer units.

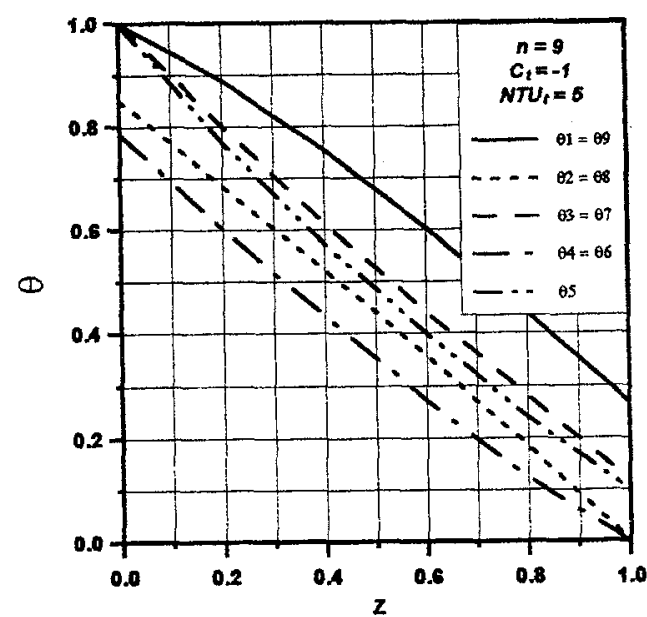

Fig. 9: Temperature distribution in a plate heat exchanger with $n=9$ and $N T U_{t}=5$.

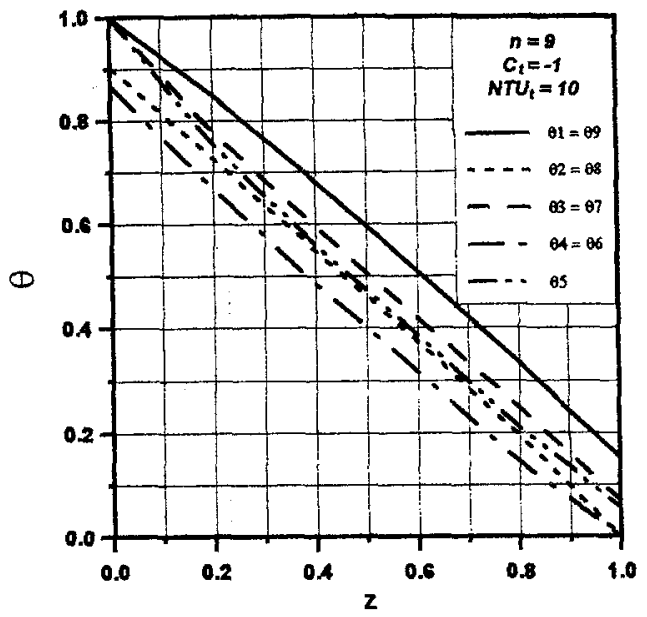

Fig. 10: Temperature distribution in a plate heat exchanger with $n=9$ and $N T U_{t}=10$.

The predicted correction factor is represented against $\varepsilon$ by Fig. 11 and against $N T U_{t}$ by Fig. 12, while the heat exchanger effectiveness is given as a function of $N T U_{t}$ in Fig. 13 for both cases of co-current and counter-current flow regimes with different values of $C_{t}$.

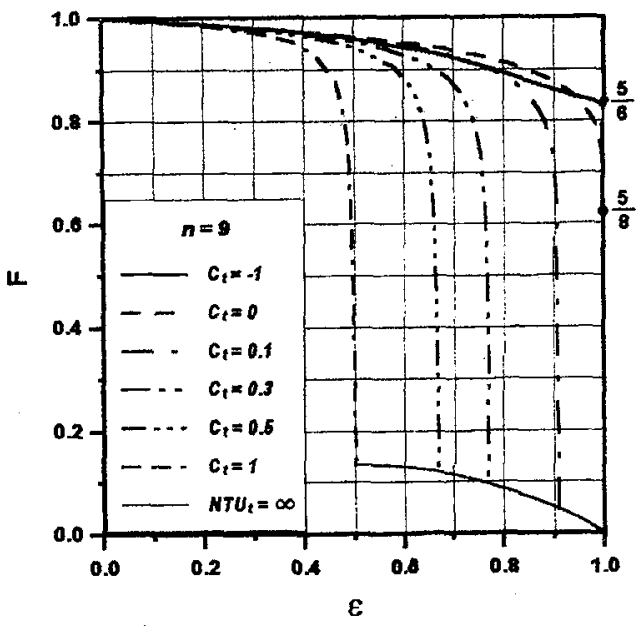

Fig. 11: Correction factor as a function of effectiveness for $n=9$.

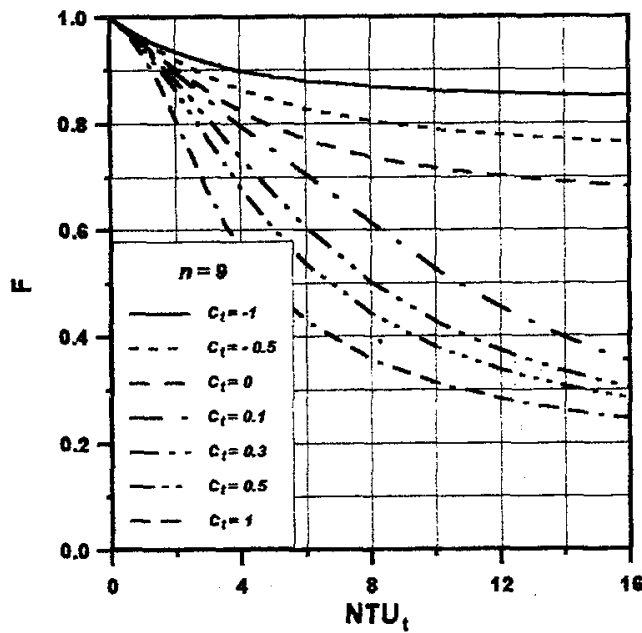

Fig. 12: Variation of correction factor with $N T U_{t}$, for $n=9$. 


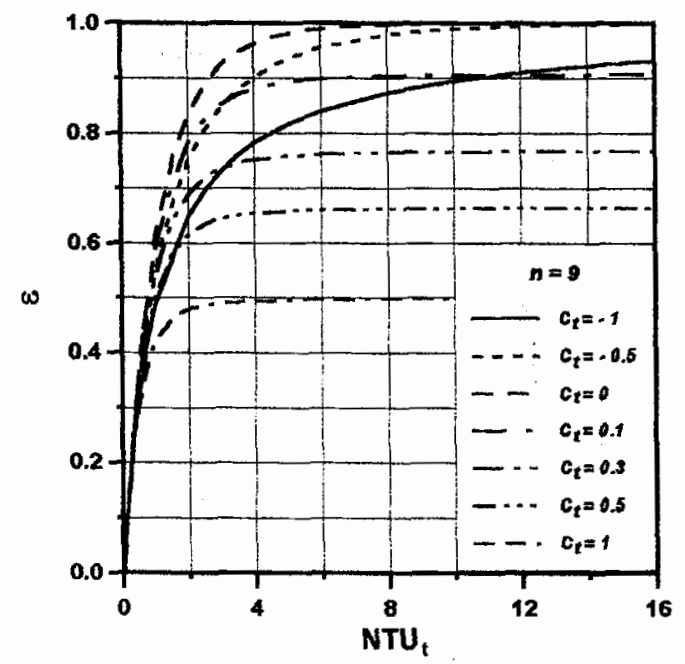

Fig. 13: Variation of effectiveness with $N T U_{t}$, for $n=9$.

It is easy to see that $F$ in the case of counter-flow lies between 1 and $\frac{5}{6}$ for $C_{t}=-1$ and between 1 and $\frac{5}{8}$ for $C_{t}=0$, while it reaches much lower values for co-current flow.

\section{Case of Eleven Parallel Channels}

The computed correction factors are given against $\varepsilon$ in Fig. 14 and against $N T U_{t}$ in Fig. 15, while the variation of $\varepsilon$ as a function of $N T U_{t}$ is shown in Fig. 16. The curves show similar behavior as already mentioned in the discussion of seven and nine channels.

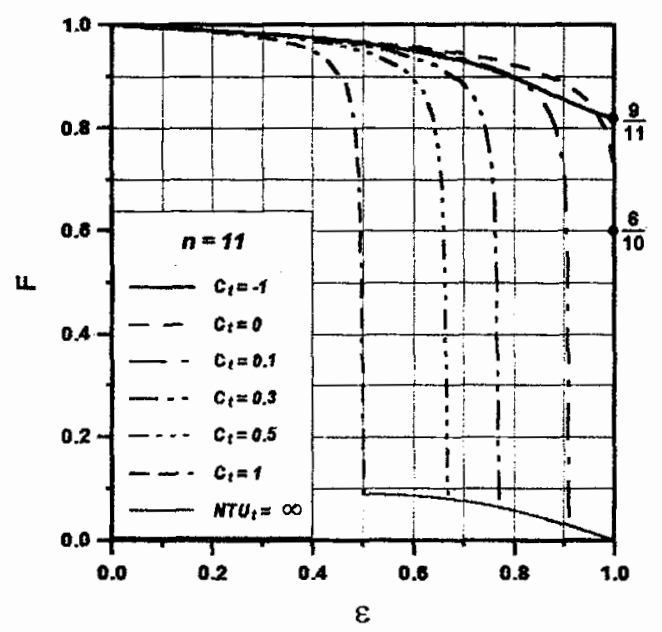

Fig. 14: Correction factor as a function of effectiveness for $n=11$.

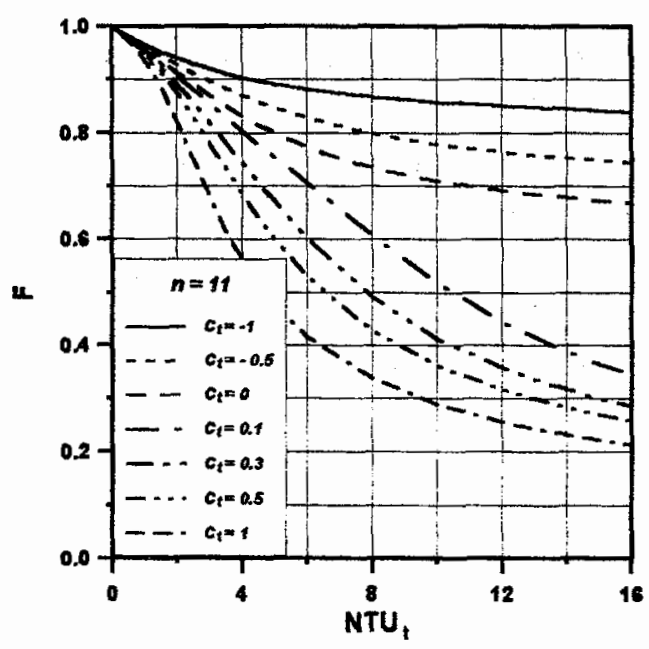

Fig. 15: Variation of correction factor with $N T U_{t}$, for $n=11$. 


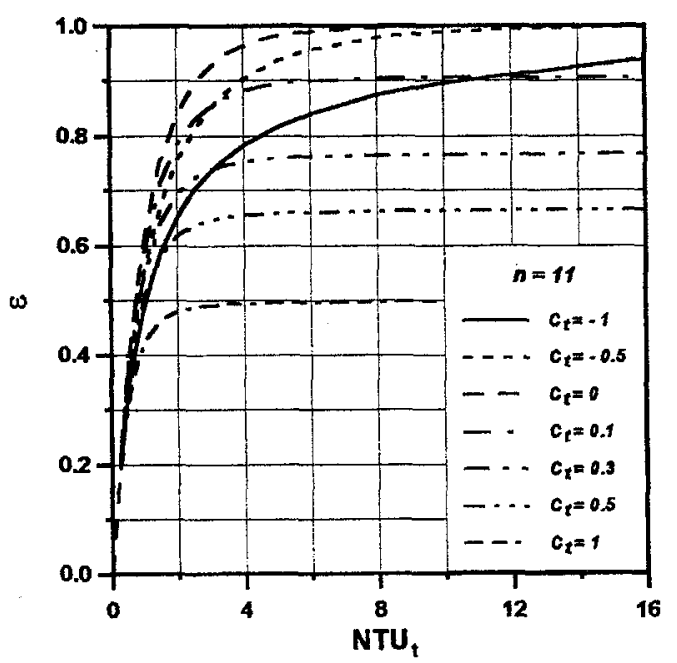

Fig. 16: Variation of effectiveness with $N T U_{t}$, for $n=11$.

The correction factor for eleven channels approaches in the limiting case $\left(N T U_{t} \rightarrow \infty\right)$ the value $\frac{9}{11}$ when $C_{t}=-1$ and the value $\frac{6}{10}$ when $C_{t}=0$.

\section{Cases of Thirteen and Fifteen Parallel Channels}

Similarly for higher odd number of channels, the numerical results for the correction factor as a function of $\varepsilon$ and $N T U_{t}$ are given by Fig. 17 and Fig. 18 respectively in case of thirteen parallel arranged channels and by Fig. 19 and Fig. 20 respectively in case of fifteen parallel channels at different values of $C_{t}$.

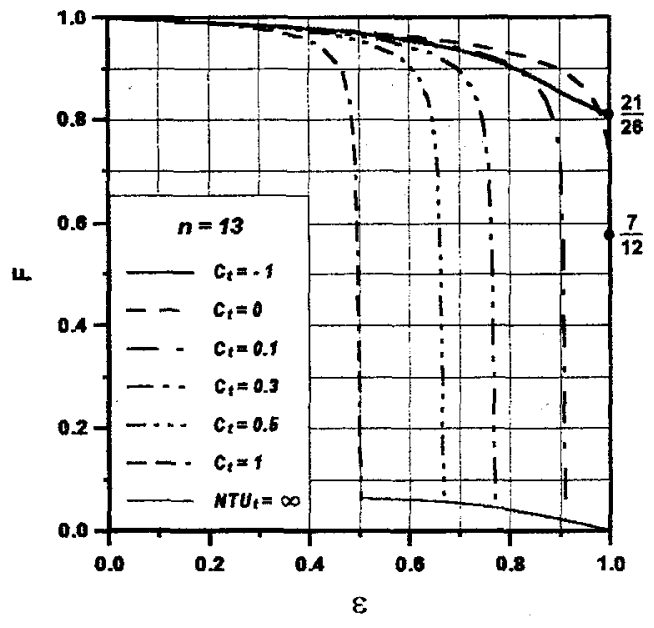

Fig.17: Correction factor as a function of effectiveness for $n=13$.

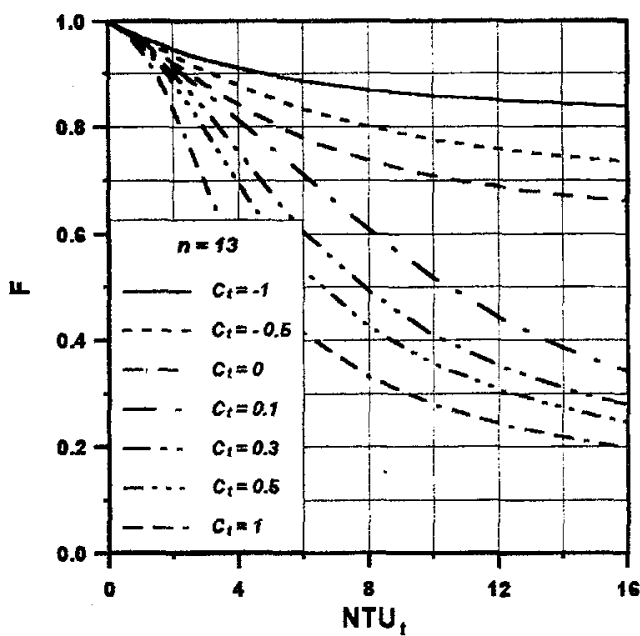

Fig. 18: Variation of correction factor with $N T U_{t}$, for $n=13$.

The variation of the heat exchanger effectiveness with both $N T U_{t}$ and $C_{t}$ is also represented in Fig. 21 for thirteen channels and in Fig. 22 for fifteen channels as well. The results indicate the same trends as in the previous cases but 
the correction factor falls with $\varepsilon, N T U_{t}$ and $C_{t}$ to reach in the limiting case a value of $\frac{21}{26}$ for $C_{t}=-1$ and $\frac{7}{12}$ for $C_{t}=0$, while it falls down steeply to approach very low values in case of co-current flow regimes.

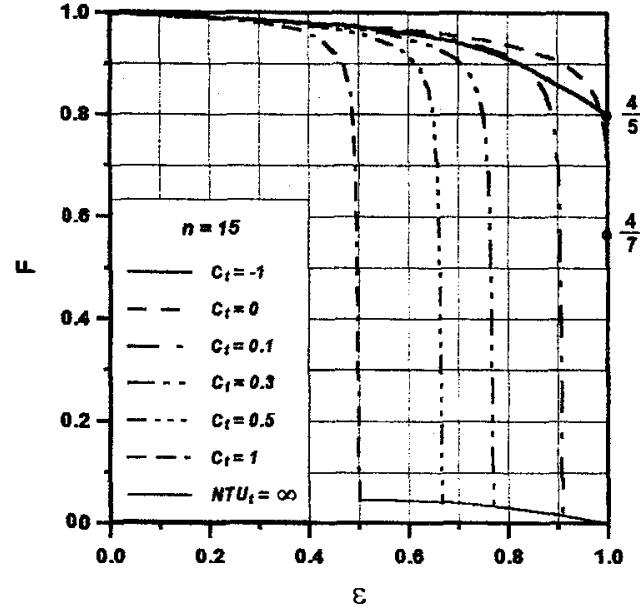

Fig. 19; Correction factor as a function of effectiveness for $n=15$.

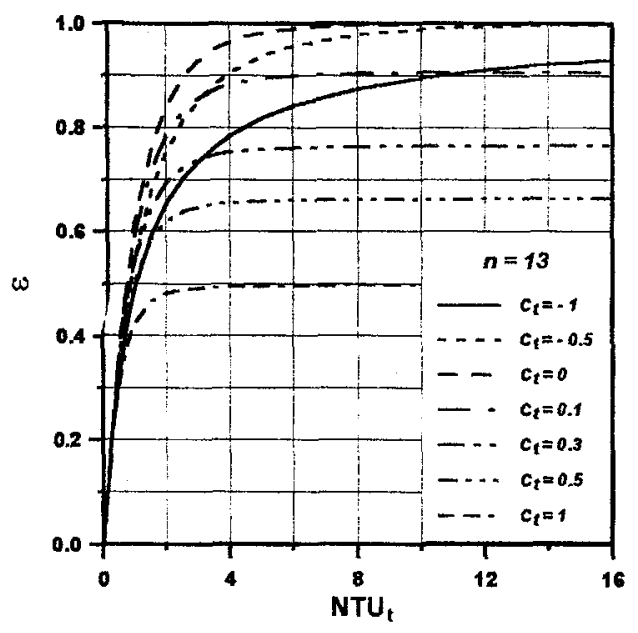

Fig.21: Variation of effectiveness with $N T U_{t}$, for $n=13$.

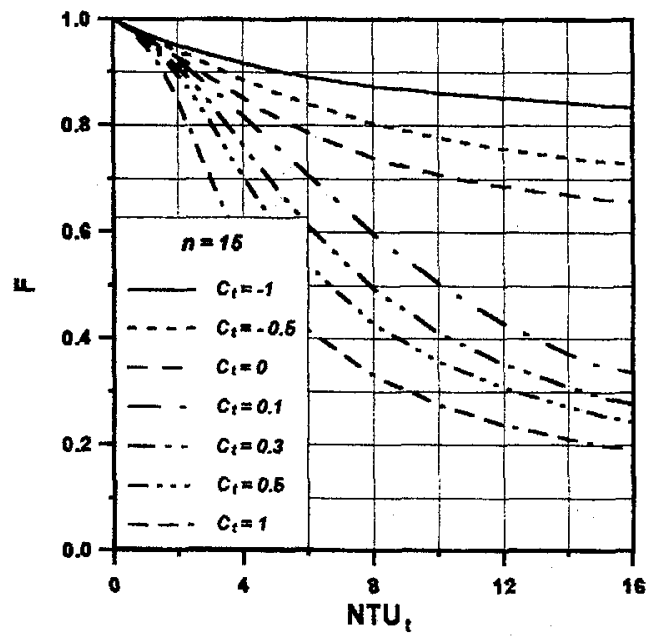

Fig.20: Variation of correction factor with $N T U_{t}$, for $n=15$.

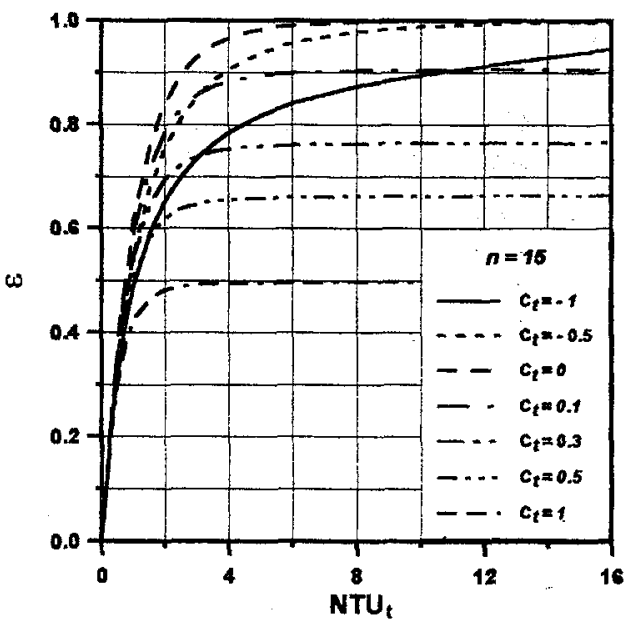

Fig.22: Variation of effectiveness with $N T U_{t}$, for $n=15$.

\section{Comparison between units of odd and even number of channels}

The correction factor as a function of the number of channels for both cases of odd and even number of channels, at different values of the heat exchanger effectiveness and for counter-flow of equal capacity rates $\left(C_{t}=-1\right)$ is represented in Fig. 23. It is clear that the correction factor equals unity for two as well as three channels, which realize the conditions of complete symmetry for both heat transfer and working media. The figures indicates also that the correction factor falls with increasing the number of channels until it reaches a 
minimum value at a certain $n$ depending on the heat exchanger effectiveness then it increases to reach one once more when the number of channels approaches $\infty$, where the effect of the two boundary channels vanishes. Figures 24 and 25 illustrate the same representation but for $C_{t}=1$ (case of parallel flow) and $C_{t}=0$ (case of evaporation or condensation) respectively.

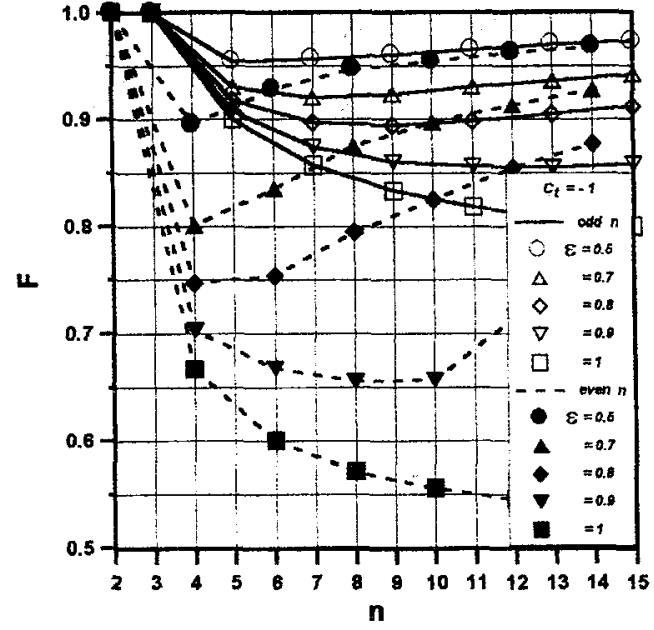

Fig.23: Variation of correction factor with the number of channels for $\mathrm{C}_{\mathrm{t}}=-1$

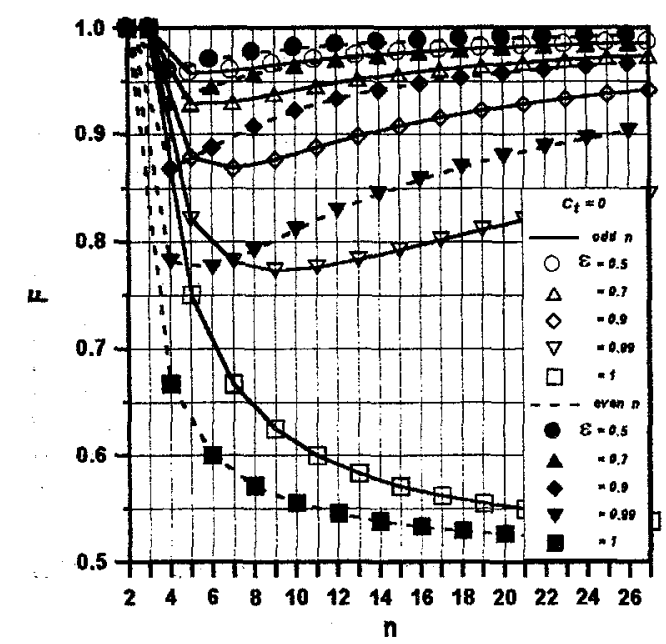

Fig.25: Variation of correction factor with the number of channels for $\mathrm{C}_{\mathrm{t}}=0$.

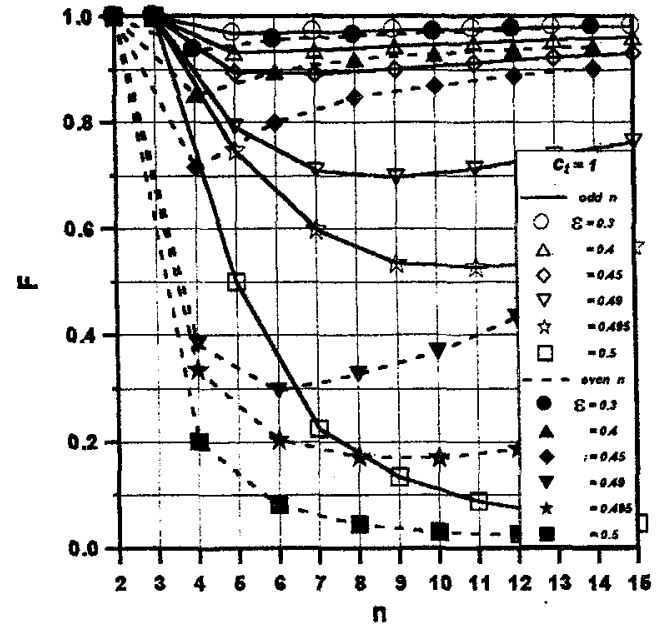

Fig.24: Variation of correction factor with the number of channels for $C_{t}=1$.

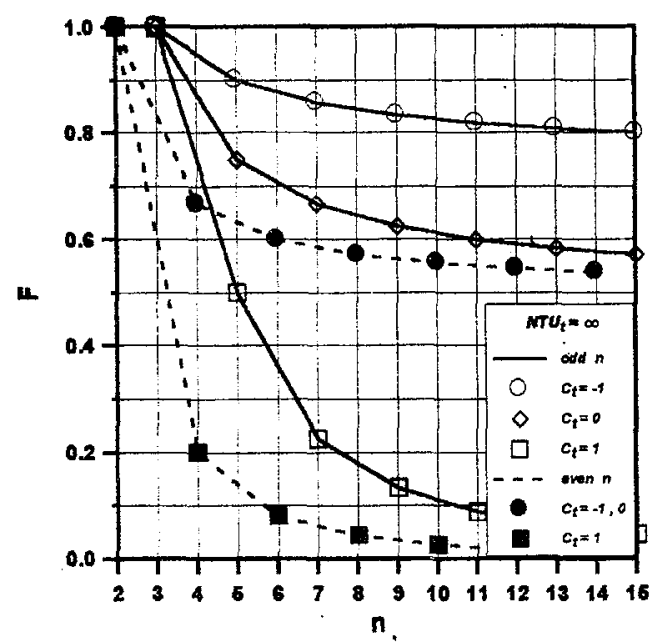

Fig.26: Variation of correction factor with the number of channels at the limit case.

It can be seen from the figures that the correction factor, or in other words, the rate of heat transfer in case of odd number of channels is more than that in case of even number of channels for plate heat exchangers having the same effectiveness in both cases of co-current and counter-current flow regimes. This is returning to the fact that in case of odd number of channels exists only one type of unsymmetry namely the heat transfer unsymmetry, while both heat 
transfer and working media types of unsymmetry take place in units with even number of parallel channels.

In case of evaporation or condensation processes in plate heat exchangers, we have the other way round. The rate of heat transfer in units with even number of channels is greater than those of odd number of channels except at the limit case $\varepsilon=1$. This is because, in case of even number of channels, one of the boundary channels will have an infinite capacity rate (i.e. constant fluid temperature) therefore, this side has no end effect. On the contrary, the two boundary channels of a plate heat exchanger with odd number of channels and $C_{t}=0$ will have finite capacity rates therefore, both will have an end effect and make the heat flow lower. In the limit case $(\varepsilon=1)$, the correction factor will be equal to the ratio of the number of streams on the low capacity rate side to the number of the thermal plates in the whole unit. For the same number of streams (for example, three streams for $n=5$ and 6 ), the number of thermal plates for odd number is less than that of even number of channels ( 4 plates for $n=5$ and 5 plates for $\mathrm{n}=6$ ), so we have $F_{\text {odd }}>F_{\text {even }}$. One can also conclude from the figure that in the limit case for units undergoing evaporation or condensation, the correction factor when $n=2 m$ is equal to that when $n=(4 m-1)$, with $m=1,2,3,4, \ldots$. Furthermore, on comparing the numerical results with the analytical predictions given by eqn.(24) for odd number of channels and eqn.(28) for even number of channels one can find an exact agreement between them.

In addition of the foregoing results at $C_{t}=0$, a comparison for the effect of varying the total heat capacity rate ratio on the correction factor as a function of the number of channels at the limit case $\left(N T U_{t}=\infty\right)$ for both cases of odd and even number of channels is shown in Fig. 26. It is noticeable that a plate heat exchanger unit with odd number of channels gives more heat transfer than a unit with even number of channels for all values of $C_{t}$ when $N T U_{t}$ approaches $\infty$, i.e. when the unit effectiveness reaches its limit value.

\section{CONCLUSIONS}

The following conclusions may be extracted from this work:

1) The possibility of the absence of heat flow over a considerable part of the internal thermal plates comes in questions. This behavior is to be expected only at high values of $N T U_{t}$.

2) The correction factor equals unity in plate heat exchanger units with two as well as three channels, which achieve the conditions of complete symmetry.

3) High rates of heat flow can be realized in plate heat exchangers in case of counter-current flow regimes specially with equal capacity rates, at low number of transfer units and with high odd number of channels, thereby the end effect tends to disappear.

4) On the contrary, very low rates of heat transfer may be obtained in plate units in case of co-current flow regimes specially with equal capacity rates, at high number of transfer units and with low even number of channels, in which the two insulated boundary channels have their worst effect on heat transfer. 
5) The correction factor decreases with increasing the number of channels in the plate heat exchanger until it reaches a minimum value at a certain $n$ depending on $\varepsilon, C_{t}$ and the art of $n$ (odd or even) then it increases to approach unity once again.

6) The rate of heat transfer in plate heat exchanger having odd number of channels is higher than that of units with even number of channels under all operating conditions except in case of evaporation or condensation we have the other way round. This means any excess plate would change the performance of the plate heat exchanger obviously.

7) In the limit case, the correction factor approaches the following values:

$$
\begin{aligned}
& F_{\infty}=\frac{n}{2(n-1)}, \text { for even number of channels with counter-flow or } C_{t}=0 \\
& F_{\infty}=\frac{n+1}{2(n-1)}, \text { for odd number of channels and } C_{t}=0 . \\
& F_{\infty}=\frac{3}{4} \frac{(n+1)}{n}, \text { for odd number of channels and } C_{t}=-1 \\
& F_{\infty}=-\frac{\lambda_{s}}{\left(1+C_{t}\right)} \frac{(n+1)}{2(n-1)}, \text { for odd number of channels and all values of } C_{t}
\end{aligned}
$$

except $C_{t}=-1$ we apply the third equation. When $C_{t}=0$, then $\lambda_{s}=-1$ and therefore, the fourth equation will be reduced to the second equation once again. 8) For plate units undergoing evaporation or condensation $\left(C_{t}=0\right)$ in the limit case, the rate of heat flow when $n=2 m$ is equal to that when $n=(4 m-1)$, with $m=1,2,3,4, \ldots$.

\title{
NOMENCLATURE
}

\author{
$A$ heat transfer area of a single plate \\ $A^{*} \quad$ coefficient matrix \\ $a_{k m} \quad$ coefficients of the exponential functions in eqn. (13) \\ $B_{k m} \quad$ coefficient ratios, $\left(B_{k m}=a_{k m} / a_{1 m}\right)$ \\ $C$ channel heat capacity rate ratio \\ $C_{p} \quad$ specific heat of the working fluid \\ $F \quad$ correction factor of the logarithmic mean temperature difference \\ $\dot{H} \quad$ total enthalpy \\ I unit matrix \\ $L \quad$ plate length \\ $L M T D$ logarithmic mean temperature difference \\ $\dot{M}$ mass flow rate \\ NTU number of transfer units \\ $n \quad$ number of channels
}




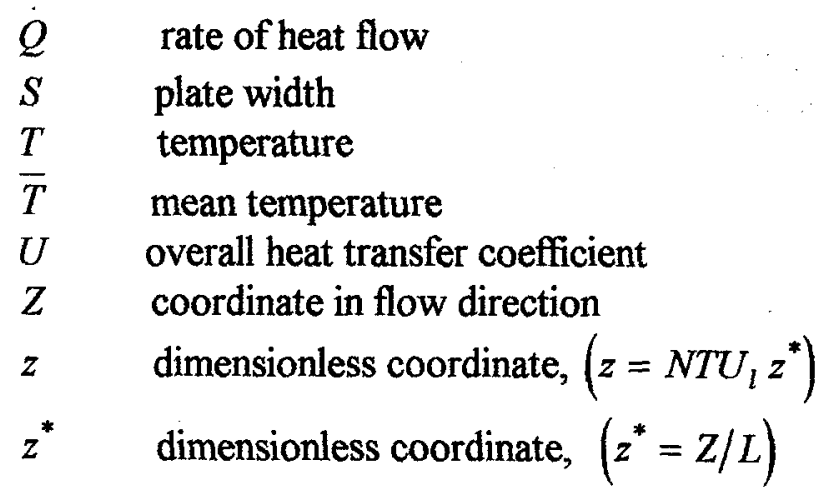

\title{
Greek symbols
}

$\Delta \quad$ difference

$\varepsilon \quad$ heat exchanger effectiveness

$\theta$ dimensionless temperature

$\bar{\theta}$ dimensionless mean temperature

$\lambda_{m} \quad$ eigenvalues

\author{
Subscripts \\ $h \quad$ high capacity rate stream \\ $i \quad$ run number of the odd-numbered channels \\ in inlet \\ $j \quad$ run number of the even-numbered channels \\ $k \quad$ stream number \\ $L M \quad$ logarithmic mean \\ $l \quad$ low capacity rate stream
}

\section{REFERENCES}

[1] Kakaç, S.; Beagles, A.E. and Mayinger, F. : "Heat Exchangers Thermohydraulic Fundamentals and Design."Hemisphere Publishing Corp., New York, (1981).

[2] Mitsumori, T.; Ikegami, Y. and Uehara, H.: "Advantages of Plate-Type Heat Exchanger over Tube-Type Heat Exchanger for OTEC Power Plant." Int. $J$. of Offshore and Polar Engineering, Vol. 9, No. 2, p. 158, (1999).

[3] Bowman, C.F. and Craig, E.F.: "Plate Heat Exchanger Performance in a Nuclear Safety-Related Service Water Application." Power ASME, PWR. Vol. 3, pp. 149-155, (1995).

[4] Bond, M.P.: "Plate Heat Exchangers for Effective Heat Transfer."The Chem. Eng., pp. 162-167, April (1981).

[5] Böhm, J.: "Wärmeübergang an Plattenwärmeaustauschern." Kältetechnik, 7. Jahrgang, Heft 12, pp. 358-362, (1955).

[6] Clark, D.F.: "Plate Heat Exchanger Design and Recent Development." The Chem. Eng., p. 275-285, May (1974). 
[7] Usher, J. : "Current Trends in Plate Heat Exchanger Design." Conference in Recent Development in Compact High Duty Exchangers, London (1972).

[8] Cooper, A.: "Recover More Heat with Plate Heat Exchangers." The Chem. Eng., pp. 280-285, May (1974).

[9] Cooper, A. and Usher, J.: "Plate Heat Exchangers." in Heat Exchanger Design Handbook, Sec. 3.7, Washington, (1983).

[10] Dummett, G.A. : "Platten - Wärmeaustauscher." Dechema Monographien, Band 26, Nr. 311, pp. 168-198, (1956).

[11] Dummet, G.A. : "The Plate Heat Exchanger in the Food Industries." Chemistry and Industry, Vol. 19, p. 1604, (1964).

[12] Eickhof, C. : " Einfuihrung in die industrielle Anwendung von Plattenapparaten." Dechema Monographien, Band 28, Nr. 363, p. 54, (1965).

[13] Seligman, R.J.S. : "The Plate Heat Exchanger in the Food Industries." Chemistry and Industry, Vol. 19, p. 1602, (1964).

[14] Flack, P.H. : The Feasibility of Plate Heat Exchangers." Chem. and Proc. Engng., p. 468, Aug. (1964).

[15] Lawry, F.:"Plate-Type Heat Exchangers."Chem. Engng.,p.89, June (1959).

[16] Parker, D. : "Plate Heat Exchangers." Chem. Engng., p.142, July (1956).

[17] Troupe, R.A., Morgan, J.C. and Prifti, J. : "The Plate Heater - Versatile Chemical Engineering Tool." Chem. Engng. Prog., Vol. 56, No. 1, p. 124, Jan. (1960).

[18] Bergmann, K. : "Plattenwärmeaustauscher in Kompaktbauweise." Verfahrenstechnik, Band 10, Nr. 6, p. 366, (1976).

[19] Steinhilper, W., Amend, P. and Borrmann, K. : "Platten- und Spiralwärmeaustauscher, Einsatz, Aufbau und Dimensionierung." Chemie - Technik, 4. Jahrgang, Nr. 1, p. 11, (1975).

[20] Cowan, C.T. : "Choosing Materials of Construction for Plate Heat Exchangers-I." Chem. Engng., p. 100, June (1975).

[21] Cross, P.H. : "The Use of Plate Heat Exchangers for Energy Economy." The Chem. Eng., p. 87, March (1982).

[22] Edwards, M.F. and Stinchcombe, R.A. : "Cost Comparison of Gasketed Plate Heat Exchangers and Conventional Shell and Tube Units." The Chem.Eng., p. 338, May (1977).

[23] Marriott, J. : "Where and How to Use Plate Heat Exchangers." Chem. Engng., p. 127, April (1971).

[24] Oliveira, H.Q. and Forslund, R.P. : "The Effect of Thermal Construction Resistance in the Design of Channel - Plate Heat Exchangers." Trans. of the ASME, J. of Heat Transfer, C 96, No. 3, p. 292, (1974).

[25] Usher, J.D. : “Evaluating Plate Heat - Exchangers." Chem. Engng., p. 90, Feb. (1970).

[26] Minton, P.E. : "Designing Spiral - Plate Heat Exchangers." Heat Exchanger Design and Specification, pp. 127-136, (1970).

[27] Wälzholz, G. : "Strömungstechnische Grundlagen der Milchpasteurisation." Dechema Monographien, Band 46, Nr. 761, p. 75, (1963). 
[28] Buonopane, R.A., Troupe, R.A. and Morgan, J.C. : 'Heat Transfer Design Method for Plate Heat Exchangers." Chem. Engng. Prog., Vol. 59, No. 7, p. 57, July (1963).

[29] Crozier, R.D., Booth, J.R. and Stewart, J.E. : "Heat Transfer in Plate and Frame Exchangers." Chem. Engng. Prog., Vol.60, No.8, p.43, Aug. (1964).

[30] Dunkley, W.L., Watson, E.L. and McKillop, A.A. : "Variation in Heat Treatment of Individual Product Particles in Plate Heat Exchangers." Food Tech., Vol. 15, p.400, Sept. (1961).

[31] Watson, E.L., McKillop, A.A., Dunkley, W.L. and Perry, R.L. : "Plate Heat Exchangers - Flow Characteristics." Ind. and Engng. Chem., Vol. 52, No. 9, p.733, Sept. (1960).

[32] Mckillop, A.A. and Dunkley, W.L.:."Plate Heat Exchangers-Heat Transfer." Ind. and Engng. Chem., Vol. 52, No. 9, p. 740, Sept. (1960).

[33] Ginstling, A.N. and Barsov, B.V.: "Performance of Plate Heat Exchangers." Brit. Chem. Engng., Vol. 5, No. 8, p. 559, (1960).

[34] Morgan, J.C., Troupe, R.A., Anderson, R.D., Cavanaugh, T. and Maranci, A. : "The Plate Heater - a Continuous Flow-Type Reactor." Ind. and Engng. Chem., Vol. 52, No. 10, p. 821, Oct. (1960).

[35] Belcher, A. : "Accommodation of varying $\theta$ values (Number of Theoretical Heat Transfer Units) within a Given Plate Heat Exchanger." Conference in Recent Development in Compact High Duty Exchangers, London (1972).

[36] Emerson, W.H. : The Thermal and Hydrodynamic Performance of a Plate Heat Exchanger - II." NEL Report No. 284, (1967).

[37] Emerson, W.H. : "The Thermal and Hydrodynamic Performance of a Plate Heat Exchanger - III." NEL Report No. 285, (1967).

[38] Emerson, W.H. : "The Thermal and Hydrodynamic Performance of a Plate Heat Exchanger - IV." NEL Report No. 286, (1967).

[39] Marriott, J. : "Performance of an Alfaflex Plate Heat Exchanger." Chem. Engng. and Proc., p. 37, Feb. (1977).

[40] Mori, S., Kataya, M. and Tanimoto, A. : "Performance of Counterflow, Parallel Plate Heat Exchangers under Laminar Flow Conditions." Heat Transfer Engng., Vol. 2, No. 1, p. 28, July-Sep. (1980).

[41] Price, A.F. and Fattah, A-F. M-A. : Hydrodynamic Characteristics of a Plate Heat Exchanger Channel." Trans. IChemE, Vol. 56, p. 217, (1978).

[42] Rosenbald, G. and Kullendorf, A.: "Estimating Heat Transfer Rates from Mass Transfer Studies on Plate Heat Exchanger Surfaces." Wärme- und Stoffübertragung, Band 8, p. 187, (1975).

[43] Rybinova, H. : "Contribution to the Problem of Heat Transfer and Pressure Drop in Plate Heat Exchangers." Verfahrenstechnik, Band 4, Nr. 9, p. 413, (1970).

[44] Sastri, V.M.K. and Mastanaiah, K. : "Heat Transfer Parameters of a Parallel Plate Heat Exchanger." Int. J. Heat Transfer, Vol. 16, p. 857, (1973).

[45] Cocks, A.M.: "Plate Heat Exchanger Design by Computer." The Chem. Eng., pp. 193-198, May (1969). 
[46] Rissler, K. : "Heat Exchanger Design by Computer." Chem. and Proc. Engng., Vol. 52, No. 10, p. 62, Oct. (1971).

[47] Cross, P. : "Preventing Fouling in Plate Heat Exchangers." Chem. Engng., p. 87, Jan. (1979).

[48] Muley, A. and Manglik, R. : "Investigation of Enhanced Heat Transfer in Low Reynolds Number Flows in a Plate Heat Exchanger." HTD., ASME, Vol. 361-3, pp. 295-302, (1998).

[49] Lee, J.; Yoon, S.; Kim, C.; Jung, D.; Seo, T. and Chun, W. : "Performance Analysis Modeling for a Plate Heat Exchanger." HTD., ASME, Vol. 361-3, pp. 483-487, (1998).

[50] Smith, V.C. and Troupe, R.A. : "Pressure Drop Studies in a Plate Heat Exchanger." A.I.Ch.E. Journal, Vol. 11, No. 3, p. 487, May (1965).

[51] Wang, L.; Sunden, B. and Yang, Q. : "Pressure Drop Analysis of Steam Condensation in a Plate Heat Exchanger." Heat Transfer Engineering, Vol. 20, No. 1, pp. 71-77, Jan-Mar (1999).

[52] Talik, A.; Swanson, L.; Fletcher, L. and Anand, N. : "Heat Transfer and Pressure Drop Characteristics of a Plate Heat Exchanger." ASME-JSME Thermal Engineering Joint Conference Proceedings, Vol. 4, pp. 321-329, (1995).

[53] Edwards, M. F., Changal Vaie, A.A. and Parrott, D.L. : 'Heat Transfer and Pressure Drop Characteristics of a Plate Heat Exchanger Using Newtonian and Non-Newtonian Liquids." The Chem. Eng., p. 286, May (1974).

[54] Jackson, B. and Troupe, R. A. : "Laminar Flow in a Plate Heat Exchanger." Chem. Engng. Prog., Vol. 60, No. 7, p. 62, July (1964).

[55] Kovalenko, L. and Obolentsev, Yu. : "Plate Heat Exchangers with Complex Shaped Heat Transfer Surfaces and their Design." Chem. Pet. Engng., Vol. 10, No. 3-4, p. 315, (1974).

[56] Muley, A. and Manglik, R. : Experimental Study of Turbulent Flow Heat Transfer and Pressure Drop in a Plate Heat Exchanger with Chevron Plates" J. of Heat Transfer, Trans. ASME, Vol. 121, No. 1, pp. 110-117, (1999).

[57] Muley, A. and Manglik, R. : 'Enhanced Heat Transfer Characteristics of a Chevron Plate Heat Exchanger for Viscous Fluid Thermal Processing Applications." HTD., ASME, Vol. 361-3, pp. 459-466, (1998).

[58] Heggs, P.; Sandham,P.; Hallam, R. and Walton, C. : 'Local Transfer Coefficient in Corrugated Plate Heat Exchanger Channels." Chemical Engineering Research and Design, Trans. ICE, Vol. 75, No. A7, pp. 641645, (1997).

[59] Bassiouny, M.K. and Martin, H. : "Flow Distribution and Pressure Drop in Plate Heat Exchangers - Part I: U- Type Arrangement." Chem. Engng. Sci., Vol. 39, No. 4, p. 693, (1984).

[60] Bassiouny, M.K. and Martin, H. : "Flow Distribution and Pressure Drop in Plate Heat Exchangers - Part II: Z- Type Arrangement." Chem. Engng. Sci., Vol. 39, No. 4, p. 701, (1984). 
[61] Bassiouny, M.K. and Martin, H. : "Temperature Distribution in a Four Channel Plate Heat Exchanger." Heat Transfer Engineering, Vol. 6, No. 2, p. $58,(1985)$.

[62] Bassiouny, M. Khalil and Martin, H. :"Heat Transfer Analysis in a Five Channel Plate Heat Exchanger with Uniform Flow Distribution." Eng. Research Bull., Faculty of Eng. \& Tech., Menoufia University, Vol. X, Part II, p. 59, (1988).

[63] Bassiouny, M. Khalil : "Experimentelle und Theoretische Untersuchungen über Mengenstromverteilung, Druckverlust und Wärmeübergang in Plattenwärmeaustauschern." Fortschritt-Berichte VDI, Reihe 6, Nr. 181, VDI Verlag, (1985).

[64] Bassiouny, M. Khalil and Martin, H. : "Temperaturverteilung in Parallelgeschalteten Kanälen von Plattenwärmeaustauschern." Chemieingenieurtechnik, 57(4), p. 330, (1985).

[65] Chowdhury, K., Bassiouny, M. Khalil, and Martin, H. : "Druckverlust und Wärmeübergang bei Spiralwärmeübertragern." 19 internationales Seminar für Forschung und Lehre in CIW, Tech. \& Phys. Chemie an der Universität Karlsruhe, July (1984).

[66] Chowdhury, K., Linkmeyer, H., Bassiouny, M. Khalil and Martin, H. : "Analytical Studies on the Temperature Distribution in Spiral Plate Heat Exchanger." Chemical Engineering and Processing, Vol. 19, No. 4, p. 183, July/August (1985).

[67] Martin, H., Chowdhury, K., Linkmeyer, H. and Bassiouny, M. Khalil : "Straightforward Design Formulae for Efficiency and Mean Temperature Difference in Spiral Plate Heat Exchanger." Proceedings of the Eight's International Heat Transfer Conference, San Francisco, USA, Vol. 6, p. 2793, (1986).

[68] Bounopane, R.A. and Troupe, R.A. : Analytical and Experimental Heat Transfer Studies in a Spiral Plate Heat Exchanger." Proc. 4th Int. Heat Transfer Conf., Paris, Paper No. HE 2.5., (1970).

[69] Wang, R.; Wu, J. and Xu, Y. : "Continuous Heat Regenerative Adsorption Refrigerator Using Spiral Plate Heat Exchangers as Adsorbers." Journal of Solar Energy Engineering, Trans. ASME, Vol. 121, No. 1, pp. 14-19, (1999).

[70] Jenson, V.G. and Jeffreys, G.V. : "Mathematical Methods in Chemical Engineering." Academic Press, London, (1963). 
آداء المبادلات المرارية ذات الالواح مع عدد قردي للتتوات د. - دمد محمد خليل بسيوني

جامعلة المبوفية - كلية المندسة - قسم هندسة القوي المكانيكية - شبين الكوم

ملخص اليحث:

يختص هذا البحث بتحليل عددي لسلوك انتقال المرارة في المبــادلات المحراريسة ذات

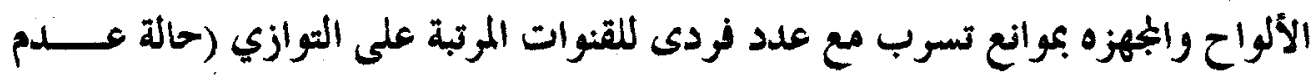

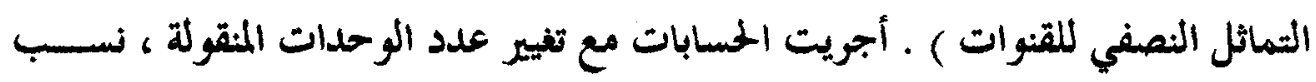

معدل السعتين الحراريتين وعدد القنوات لحالة السريان المتحد والمتضاد الاتجاه.

تم بناء بونامج حاسب آلي لكعيين توزيع درجات المحرارة فل القنوات ، فعاليسـة المبــادل

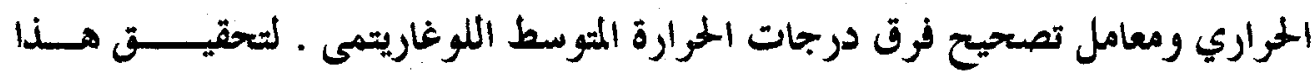

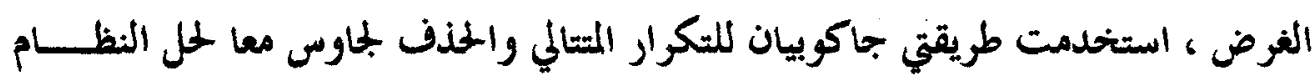

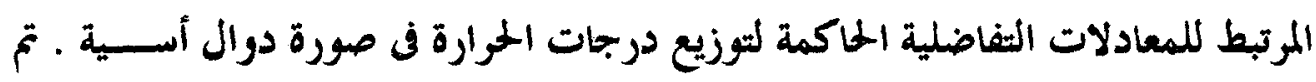

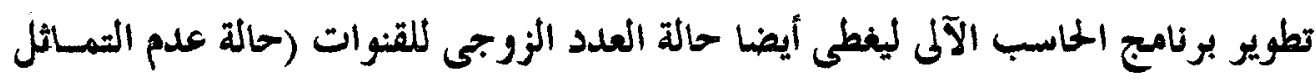

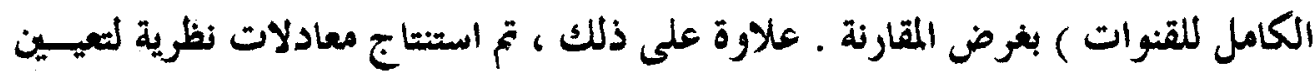

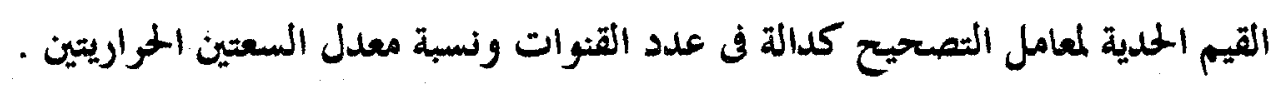

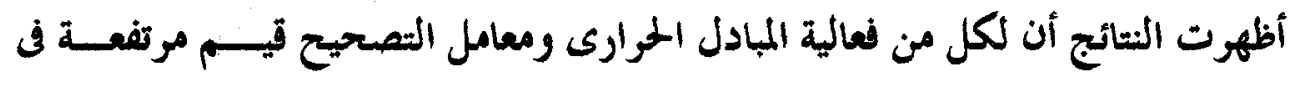

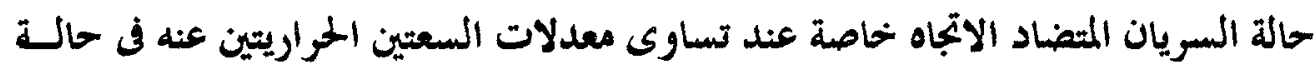

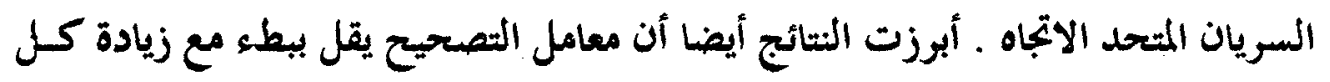

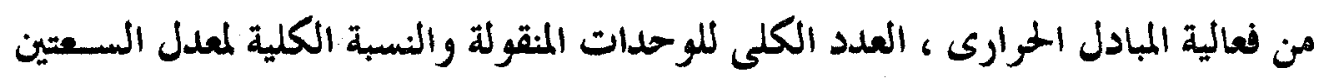

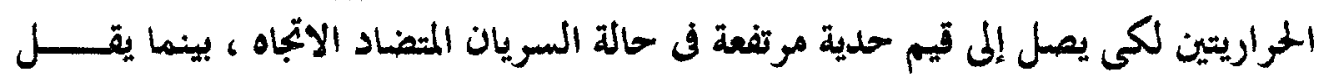

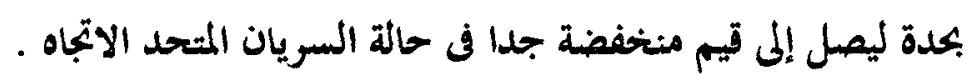

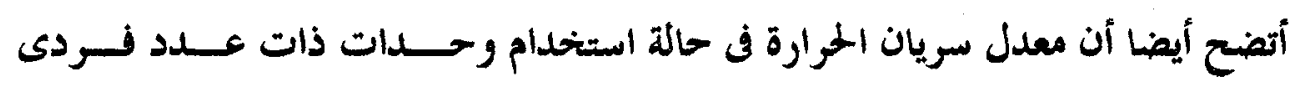

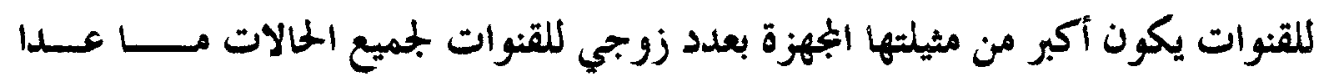

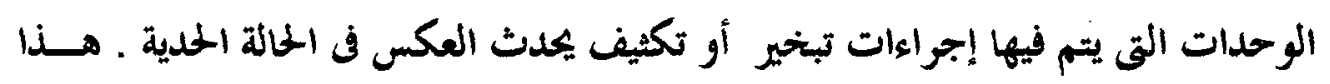

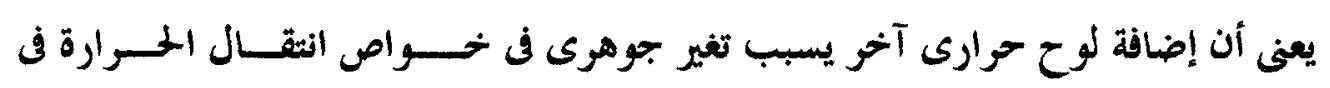

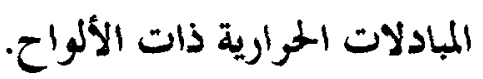

